\title{
O editor como curador: as estéticas da interrupção e da raridade nas coleções literárias contemporâneas
}

\author{
The editor as a curator: the interruption and rarity aesthetics \\ in contemporary collections
}

\author{
HUMBERTO FOIS-BRAGA \\ Universidade Federal de Juiz de Fora. Juiz de Fora, MG, Brasil.
}

\begin{abstract}
Resumo: O artigo visa discutir histórico e conceitualmente os projetos editoriais brasileiros de coleções literárias. Após um traçado histórico, analisaremos os principais modelos de distribuição adotados pelos projetos de livros vendidos em volumes. Na sequência, a partir dos conceitos de estética da interrupção, dispositivos editorais e raridade, pensaremos nas coleções brasileiras contemporâneas, com ênfase na "Amores Expressos" (Cia. das Letras). Percebe-se que as coleções contemporâneas tendem a ser multiautorais e com temáticas que constituem uma originalidade a partir da escrita encomendada. Se as coleções são formas de comercialização e de construção de discursos, sugerimos que algumas obras, enquanto volumes de uma coletânea, devam ser analisadas levando em consideração o posicionamento de campo e o diálogo temático que desenvolvem entre si.
\end{abstract}

Palavras-chave: Projetos editoriais; Coleções literárias; Amores Expressos.

\begin{abstract}
We aims to discuss historically and conceptually the editorial projects of Brazilian literary collections. After a historic outline, we intend to analyze the main distribution models adopted by the book projects sold in volumes. Next, based on concepts of interruption aesthetics, editorial devices and rarity, we aim to analyze contemporary Brazilian collections, namely "Amores Expressos" (Cia. das Letras). Contemporary collections tend to be multi-author and have themes that constitute originality from the ordered manuscript. If collections are a way of commercialization and discourse construction, we suggest that some work should be analyzed taking into account the field positioning and the thematic dialogue that they develop amongst themselves.
\end{abstract}

Keywords: Editorial projects; Literary collections; Amores Expressos.

\section{Introdução}

A partir de diversos vestígios levantados, visamos traçar uma arqueologia das coleções literárias brasileiras, para com isso percebermos suas nuances que culminaram com as novas propostas editorais que vemos ocorrer na contemporaneidade. Para tal discussões, nosso foco estará nas coleções literárias temáticas, em oposição às que compõem séries literárias. Aqui, faz-se necessário um esclarecimento a respeito dos termos: entendemos como seriadas aquelas coleções pautadas em uma única narrativa que perpassa diversos volumes, enquanto na temática cada obra constitui um enredo fechado em si. Na primeira situação, a história interrompida no volume um continua no dois, exigindo uma sequência lógica de leitura; já no segundo caso, temos uma leitura que não se vê presa a uma ordem (embora os lançamentos cadenciados e a numeração do volume possam induzir a uma sequência). Por isso, definimos como coleção temática aquela totalidade composta por obras lançadas em volumes independentes em termos narrativos, mas que constroem entre si uma transtextualidade a partir de um argumento comum aglutinador proposto pelo projeto editorial (FOIS-BRAGA, 2016).

Em um primeiro momento, apresentaremos um contexto histórico sobre as coleções literárias brasileiras, desde o século XIX até o século XX. Já no segundo tópico, avançaremos para compreender o conceito de raridade e exclusividade que perpassam as coleções e, assim, discutiremos as coleções que surgem a partir de obras sob encomenda, sendo esta uma tendência editorial que se fortalece a partir do último decênio do século XX 
e adentra no XXI. Neste instante, analisaremos aquilo que consideramos como sendo os dispositivos editoriais modeladores das coletâneas, com ênfase ilustrativa na coleção Amores Expressos.

Por dispositivo, entendemos os mecanismos prescritos que operam na estrutura do livro-volume constituído como a parte fragmentada de um todo colecionável. Adotamos os seguintes elementos como referências dos dispositivos desta estética da interrupção inscrita nas coletâneas: (1) a definição dos fragmentos temáticos, (2) a quantidade de volumes a compor a coleção, (3) a periodicidade de seus lançamentos e (4) a construção de uma unicidade visual dos volumes via design dos livros.

Esperamos, com isso, trazer uma contribuição histórico-teórica sobre os projetos editoriais de coleções no contexto brasileiro e, assim, entenderemos que as obras colecionáveis deveriam ser analisadas para além de seu conteúdo literário, levanto também em consideração o diálogo temático gerado pelos volumes.

\section{Percursos históricos das coleções literárias brasileiras}

As coleções literárias, enquanto projetos editoriais, atendem às mais diversas funções, dentre as quais destacamos, por um lado, o interesse do mercado livreiro em desenvolver novas formas de consumo capazes de fidelizar uma clientela leitora convertida em colecionadora, impulsionando compras seriadas a partir da vontade de completar um conjunto proposto. Por outro lado, tais coleções também atendem a um processo de seleção e hierarquização daquilo que é considerado importante a ser lido - ao dizer que aquelas obras compõem, por exemplo, "os clássicos da literatura brasileira", o projeto editorial coloca em evidência, enquanto varre para as margens, alguns textos que considera como representativos da literatura nacional, construindo com isso um certo alento para o leitor, que vê nestes volumes uma função de completude em sua formação - supostamente, ao se ler todos os volumes da coleção "clássicos da literatura brasileira", o leitor-colecionador teria um panorama sobre aquelas obras e autores considerados os mais representativos de tal temática nacionalista.

Coleção é, pois, um recorte de uma totalidade inabordável - como ler tudo já produzido pela literatura (inter)nacional? Com isso, como sugere Olivero (1999), não é por acaso que elas surjam com o sugestivo nome de "Biblioteca" (Bibliothèque) fortalecendo-se na França a partir do século XIX, quando ocorre uma explosão de novos títulos e a ampliação do público leitor. Neste momento, os editores veem nestas bibliotecas temáticas uma estratégia de segmentação do mercado livreiro, conciliando o gosto de diferentes públicos a uma oferta específica que os atenda.

Em sua extensa obra denominada $O$ livro no Brasil, Laurence Hallewell (2012) relata a constituição do mercado editorial brasileiro e, assim, em diversos momentos, comenta sobre a questão das coleções lançadas pelas editoras. Em uma leitura transversal, centrada neste mapeamento sobre o papel das coleções no sistema literário nacional, podemos desprender empreitadas interessantes que se iniciaram ainda no século XIX. De acordo como o autor, foi a partir de 1860, através do livreiro-editor Baptiste Louis Garnier, que se iniciou no Brasil uma ampla publicação de romances em formato de livros:

Seu interesse [de Baptiste Louis Garnier] pode ter sido despertado por uma nova moda entre os compradores brasileiros de livros: a posse de coleções de seus autores favoritos. Isso poderia explicar sua predileção por edições uniformes das 'obras' de um autor. Embora raramente arriscasse publicar o primeiro livro de um autor, ninguém editou, nesse período, mais livros brasileiros de ficção do que B. L. Garnier, e praticamente não houve um romancista brasileiro de importância que não acabasse tendo a maioria de suas obras publicadas por ele (HALLEWELL, 2012, p. 238) [inserção nossa].

No critério editorial da Garnier, no final do século XIX e início do XX, prevalecia a tendência em publicar autores conhecidos e cujas vendas eram asseguradas e, com isso, vemos que o formato das primeiras coleções temáticas brasileiras tinha o argumento aglutinador direcionado em torno da ideia de um único autor e todas as suas obras:

o editor preferia, claramente, obras que pudesse publicar em coleções, em que a oferta de algum título individual atrairia o leitor, levando-o a adquirir outros volumes da série. Isto se aplicava aos autores já falecidos cujas obras pudessem ser reeditadas numa coleção completa [...]; ou de um escritor consagrado de quem se pudesse esperar o acréscimo de outras obras similares a uma coleção já existente (Machado de Assis) [...]. Por outro lado, a obra isolada era um risco que, mesmo no caso de transformar-se em grande sucesso editorial, não levava a nada (HALLEWELL, 2012, p. 289).

Se o autor morto já apresentava a vantagem de oferecer ao editor uma visão da totalidade de suas obras, o que permitia prever quantidade de volumes e delimitar início e fim do projeto editorial destas antologias, os ainda vivos abriam uma indefinição na própria ideia de coleção, pois o número real de volumes era sempre uma incógnita cujos lançamentos eram dependentes do tempo de escrita. Ou seja, de um lado, todas as obras já estavam postas e 
eram vistas a partir de um panorama concluído com a morte do autor, enquanto, do outro, a publicação de obras inéditas deveria ocupar um lugar específico nesta coleção em progresso.

Também é digna de nota a recusa de Garnier em publicar obras individuais, fora de uma coleção: em termos mercadológico, um único sucesso não valia tanto a pena quanto a construção de um hábito de compra seriada alavancada pelo colecionismo - entre o best-seller de uma única obra e as coleções, ele preferia a segunda e suas vendas recorrentes.

Já na primeira metade do século XX, fortalecem-se as coleções literárias pautadas em traduções de autores estrangeiros e que visavam um revisionismo da literatura nacional e mundial. Com essas traduções, diversas obras, até então acessíveis somente em outras línguas, foram incorporadas ao sistema literário brasileiro a partir de uma sagaz estratégia mercadológica: ao inserir, como volume e dentro de uma coletânea, ao menos uma obra de tradução inédita, o editor estava servindo da exclusividade desta primeira edição em língua portuguesa para atrair o leitor a uma compra sequencial, direcionando seu interesse para os demais volumes que comporiam o quadro.

Portanto, em paralelo com as coleções temáticas que giravam em torno de obras completas de um determinado autor, abundavam coleções multiautorais que reagrupavam clássicos literários a partir de títulos como Coleção Nobel, da década de 1930/1940, e A Biblioteca dos Séculos, ambas da Editora Globo do Rio Grande do Sul; Coleção Saraiva de Clássicos Brasileiros, de 1944, que era comercializada pelo clube do livro com tiragens de cinquenta mil exemplares; e a Biblioteca de Literatura Brasileira, da Martins Editora, cujas obras como Memórias de um Sargento de Milícias e Iracema eram acompanhadas de ilustrações inéditas de artistas como F. Acquarone e Anita Malfatti.

Ao longo da segunda metade do século XX, o mercado de coleções foi se especializando e se segmentando entre diferentes públicos, com lançamento de coletâneas temáticas direcionados aos jovens, como as de contos (Jovens de Todo o Mundo, de 1960, e Contos Jovens) bem como as de romances (Primeiros Voos e Cantadas Literárias, da década de 1980, todos da Ed. Brasiliense). Um outro projeto de coleção com grande apelo ao imaginário infanto-juvenil brasileiro é a Vaga-lume, da Editora Ática, que vem sendo produzida desde 1972.

Mas, e talvez, um das editoras mais proeminentes na elaboração de coleções literárias temáticas tenha sido a José Olympio, que desde as décadas de 1940 vinha com empreitadas neste modelo de projeto editorial, principalmente a partir das coleções Romances da Vida, direcionada às traduções de biografias históricas, e Rubaiyat: Joias da Poesia Universal, quando vários poetas foram traduzidos para o português. Porém, é na segunda metade do século $\mathrm{XX}$ que a referida editora trouxe maiores inovações para o mercado das coleções de livros:

durante os anos de 1950, a José Olympio interessou-se por coleções ilustradas de clássicos da literatura brasileira e de obras sobre o Brasil. Começou, em 1951, com uma edição de dezesseis volumes de toda a ficção de José de Alencar, com introduções escritas por proeminentes autores da época. No ano seguinte, publicou o que se afirmava ser a primeira tradução brasileira de Dom Quixote (HALLEWELL, 2012, p.514).

Aqui, um fato curioso: se as obras de José de Alencar compunham aquilo que estamos chamando de coleção temática, Dom Quixote foi uma serialização, posto que a obra saiu fragmentada em 05 volumes colecionáveis. A partir deste ano, novas coleções seriam lançadas pela editora, ditando um formato cujo diferencial nem sempre se encontrava nos textos, posto que estes normalmente eram republicações, mas na forma de suas apresentações, principalmente com ilustrações exclusivas ou prefácios encomendados a especialistas, como ocorreu com a coleção Fogo Cruzado, iniciada em 1940 e que visava à publicação de grandes escritores mundiais, assim como uma outra que saiu em 10 volumes e dedicada às obras completas de Dostoiévski. Também lançou, ainda na década de 1950, coleções completas de obras de autores como Oliveira Vianna (15 volumes), de G. Casanova (10 volumes, intitulado Memórias), História dos Fundadores do Império do Brasil (10 volumes), História do Brasil (07 volumes), e a Coleção Sagarana, entre 1973 e 1974, com reimpressão de obras literárias brasileiras modernas.

É na editora José Olympio que também vemos projetos editoriais de coleções sendo interrompidos devido à pouca venda, como a dedicada à Charles Dickens, lançado somente até o segundo volume (eram previstos 30), e aquela que visava publicar obras completas de Tolstói, idealizada em doze volumes e com ilustrações, mas que nunca saiu. É também em tal editora que encontramos um dos primeiros exemplos de uma literatura sob encomenda para compor coleção: na comemoração dos quatro séculos de fundação da cidade do Rio de Janeiro, uma coleção em seis volumes intitulada Rio Quatro Séculos veio à público,

com colaborações de Carlos Drummond de Andrade, Vivaldo Coaracy, Manuel Bandeira e Gastão Cruls, ricamente ilustrada com estampas fotográficas, reproduções de ilustrações de Debret, Rugendas e outros, e desenhos e traços de Luís Jardim, Geroge Bloow etc. Essa coleção constitui um excelente exemplo do estilo da 'Casa' na época: um projeto adequado, atraente, imediatamente reconhecível como 'da José Olympio' - e, no entanto, surpreendentemente econômico (HALLEWELL, 2012, p. 517). 
Sob o epíteto de colaboração, há a ideia de uma escrita direcionada. E, neste modelo, ainda vemos emergir uma proposta de intermidialidade, cuja exclusividade da coletânea está no diálogo de novos textos com antigas ilustrações - ao contrário de outras coleções da editora, que até então tinham novas ilustrações para antigos textos ${ }^{1}$. Além disso, como a citação acima deixa explícito, a José Olympio levou o conceito de coleção a um outro patamar de sofisticação, sendo que o apelo de raridade, necessária a qualquer ato de colecionismo, estaria para além do conteúdo, sendo encontrado também no acabamento, ou melhor, na exclusividade do suporte dos volumes que compunham a coletânea.

Quando se fala em coleções, temos que refletir para além dos conteúdos literários que as compõem, já que existem questões sobre os canais de distribuição e os formatos dos suportes adotados pelas editoras. Assim, na história brasileira das coletâneas, vimos que o clube de livros da Saraiva possibilitou uma tiragem acima da média para os volumes que compunham os seus Clássicos Brasileiros; mas, outro canal de distribuição adotado foi o de venda de porta em porta, em que o modelo mais viável de coleções era aquele cujos volumes seriam comercializados todos de uma só vez através da intercepção do leitor em seu próprio lar. Neste tipo de canal de distribuição, a editora Jackson sobressaiu com suas vendas, inclusive lançando, em 1937 e em 31 volumes, a obra completa de Machado de Assis - fato curioso é que José Olympio, em 1934, buscou comprar os direitos autorais de tal autor, perdendo-o para a referida editora, e "sua decepção não foi tanto por ter perdido uma mina de ouro, mas por temer que a política de Jackson de vender apenas coleções completas estancasse o crescimento do natural interesse em Machado de Assis através da compra casual de volumes avulsos" (HALLEWELL, 2012, p.517). Nesta percepção da José Olympio, o cadenciamento nas publicações dos volumes geraria um hábito mais arraigado de leitura do que a entrega, em um único pacote, de todas as obras, pois o sentimento de totalidade acabaria por inibir a vontade de mergulho literário na individualidade dos livros.

No quesito formato, ao mesmo tempo que se buscava constituir coleções luxuosas para um "status de prateleira", também se visava aumentar as margens de lucro a partir de uma maior vendagem com uma produção de baixo custo. Neste âmbito, os livros de bolso foram

\footnotetext{
1 José Olympio ainda chegou a contratar Candido Portinari para realizar ilustrações para uma nova coleção de Dom Quixote e outra de Vidas Secas, porém, com a morte do artista, os projetos ficaram suspenso, deixando pronto somente vinte e duas ilustrações para a obra do romancista espanhol. E "estas ilustrações inspiraram 21 poemas de Drummond de Andrade, que foram publicados juntos, mas sem o texto de Cervantes, por outra editora, José Aguilar, dois anos antes da morte do pintor" (HALLWELL, 2012, p. 515).
}

testados, e se existem exemplos da década de 1930, com a Coleção Globo, foi a partir de 1960 que as estratégias neste formato se intensificaram com a coleção Sagarana da José Olympio, a Brasiliense de bolso em 1970, bem como o surgimento da Editora Edibolso em 1971. Mas, como sugere o autor, as coleções de bolso nunca fizeram sucesso no Brasil, "talvez o próprio conceito de produto barato descartável ainda seja estranho ao consumidor brasileiro, extremamente conservador, sobretudo numa área de prestígio como a da "cultura" (HALLEWELL, 2012, p. 746). A partir desse descrédito do leitor em relação aos livros de bolso, a Editora Abril, na década de 1960, encontrou a sua fórmula de sucesso para as coleções: volumes comercializados em bancas de jornais.

Considerada um referência na industrialização dos livros nos anos de 1970, a Editora Abril vem investindo há décadas neste conceito de coleções temáticas, comercializando volumes lançados regularmente nas bancas de jornais. Como nos relata a pesquisadora:

O número de vendas de livros em papelarias e bancas de jornal é quantitativamente mais significativo: em $1973,9,6 \%$ do total dos livros comercializados foram vendidos em papelarias e 2,2\% em bancas de jornal; em 1979, 6,0\% foram distribuídos em papelarias e $20,9 \%$ em bancas de jornal. Quem mais se beneficiou das bancas de jornal como pontos de venda de livros foi a Editora Abril, com suas coleções de livros e de fascículos a serem encadernados. A Bíblia mais Bela do Mundo foi o primeiro empreendimento (1965) da Abril no setor de fascículos. Para sua distribuição e comercialização, a Abril utilizou a rede de dezoito mil bancas que já estava montada no país em função da distribuição das revistas da editora. A partir daí seguem-se muitas outras coleções, entre as quais a coleção de livros de filosofia Os Pensadores iniciada em 1974 e a de livros de economia, Os Economistas, iniciada em 1982. As tiragens oscilavam entre cincoenta mil e quinhentos mil exemplares. Um claro caso de industrialização profissional da produção e da comercialização editorial (REIMÃO, 1996, p. 62).

Ainda de acordo com Hallewell (2012), Os Pensadores vendiam cem mil exemplares por semana, e em Os Economistas, dos cinquenta autores publicados, vinte nunca tinham sido lançados antes no Brasil. Tais coleções de banca da Editora Abril eram projetadas para durar 02 anos, algumas com lançamentos semanais e outras quinzenais; e se começou com traduções, pouco a pouco a editora estreou na produção de conteúdos próprios, inclusive exportando-os. A editora também inovou com a inserção de discos em suas coleções sobre música, e com kits de experimentos científicos caseiros na coleção Os cientistas, expandindo a ideia de coleção de livros para a de outros objetos vinculados à temática. 
Para além destas coletâneas de livros de cunho social, científico, filosófico e político, o selo Abril Cultural, responsável pelo lançamento de livros nas bancas de jornais entre 1968 e 1982, editou coleções literárias como Os Imortais, Clássicos Modernos, Clássicos da Literatura Infantil, etc. A coleção Grandes Sucessos, que era focada na publicação de obras consideradas best-sellers, surgiu no segundo semestre de 1980; e lançando um título por semana, com uma tiragem em torno de cem mil exemplares por obra, ultrapassou em muito a média dos cinco mil exemplares referente aos livros normais de ficção publicados individualmente e a de dez mil dos de bolso (HALLEWELL, 2012). Com tais resultados, a venda de coleções temáticas em bancas tornou-se um negócio lucrativo que chamou a atenção de outras empresas, como a Ed. Globo e a Record, esta estreando seus projetos editoriais de coleção com o foco em temáticas autorais, tendo uma direcionada às obras de Agatha Christie e outra às de Jorge Amado.

Estratégia de venda utilizada até hoje, e facilmente comprovada ao se ir em qualquer banca de jornal, as editoras de diversos periódicos vêm utilizando seus canais de distribuição já estabelecidos para alavancar vendas a partir da criação de coleções temáticas. Sendo lançadas em volumes, eram às vezes adquiridas pelos leitores a partir de uma venda exclusiva e "casada", como nos dizia a informação na contracapa da Coleção Livros O Globo, que em 1997 publicou quinze clássicos da Literatura em Língua Portuguesa: "esta obra foi publicada com exclusividade pelo jornal $O$ Globo e não pode ser vendida separadamente".

Vale lembrar que tal estratégia dos volumes, comercializados nas bancas de jornais, mantém a expectativa dos leitores, quando na edição da revista/ jornal de hoje traz uma matéria que mescla reportagem e publicidade sobre a obra que acompanhará o periódico de amanhã; ou quando na contracapa de cada obra vem a lista de todos os volumes a serem lançados, para que, desde o início, o leitor tenha a sensação de estar acompanhando o desenrolar lento de uma coleção.

\section{A raridade e os dispositivos editoriais nas coleções}

Podemos perceber algumas tendências emergindo destes vestígios históricos deixados pelas coleções temáticas produzidas pelas editoras brasileiras. Primeiramente, como percebemos com a Martins Editora e a José Olympio, há sempre um toque de raridade para atrair colecionadores, sejam novas ilustrações para antigos textos, sejam novos escritos para antigas gravuras, em que o suporte dos volumes são também considerados de fino acabamento para construir o status de exibição nas prateleiras. Esta sensação de exclusividade também pode ser vista na Editora Abril, com a inserção de discos e demais apetrechos nos volumes vendidos, fazendo com que duas coleções corram e se construam em paralelo - a do livro e a do objeto que o acompanha. Há também os projetos editoriais que constroem esta raridade necessária ao colecionismo a partir da inserção de obras inéditas em meio a outros romances já banalizados, sendo este o caso de volumes que trazem a primeira tradução em língua portuguesa de autores estrangeiros ou a publicação da primeira edição da obra de um determinado escritor nacional.

Nesta perspectiva, o editor de coleções temáticas é um curador, que seleciona autores e textos a partir de um conceito expositivo, dando-lhes um sentido para além de suas individualidades, construindo uma teia de significados que extrapola cada romance e os interliga a partir de uma ideia de ineditismo - para Obrist (2014, p. 09), o ato curatorial consiste, basicamente, em "conectar culturas, aproximando seus elementos: sua tarefa é fazer conexões e permitir que esses diferentes elementos se toquem. Você pode descrevê-lo como [...] uma forma de mapeamento que abre novas rotas por uma cidade, um povo ou um mundo". Em uma percepção curatorial, os livros de uma coleção tornam-se visíveis à partir de diversas decisões tomadas pelo editor: a temática que constrói um discurso unificador, as deliberações sobre quem participa e quem está excluído, e as possibilidades de ditar a sequência de lançamento das obras, constituindo um percurso expositivo de leitura.

Ishibashi (2007, p.24) nos diz que "tudo que esperamos de um editor trata de uma impossibilidade: a sua não existência". O editor enquanto curador é a afirmação dessa existência, pois se algumas vezes ele traz em seu nome uma grife que valoriza os textos que decide lançar, enquanto organizador de uma coleção ele é sempre a presença espectral que insinua um bastidor que organizou intencionalmente a temática e que filtrou autores e obras. Por isso, o editor que se quer curador é, também, um selecionador, já que uma coleção sempre impõe limites sobre o que será publicado e descartado, bem como sobre as características de exclusividade que comporão os dispositivos editoriais modeladores do conjunto.

Consequentemente, este panorama temático que tais coleções propõem é, acima de tudo, um discurso construído pelo editor que organizou, a partir de certos critérios técnicos e subjetivos, aquelas obras que considera legítimas para integrar os volumes que estarão enfileirados nas estantes: em última instância, o editororganizador é o colecionador primeiro.

Com essa busca da raridade, necessária ao colecionável, levada à última potência, as coleções literárias 
programadas exclusivamente com obras inéditas parecenos ser algo bastante contemporâneo no mercado editorial brasileiro, pois sendo produzidas com exclusividade, elas atraem um público que só terá acesso a elas a partir da compra daqueles volumes. Enquanto a coleção temática que republica obras constrói seu discurso de raridade a partir do paratexto literário (e.g. edições de luxo, prefácios assinados por especialistas, resumos bibliográficos do autor e do contexto histórico de onde a obra emergiu, fichas interpretativas para direcionar a leitura, notas explicativas, ilustrações, brindes, etc.), as coleções de obras inéditas atrai o colecionador pelas ideias de raridade e exclusividade contidas no próprio texto literário.

Em suma, e a partir deste traçado histórico, parecenos que a construção da raridade nas coleções começou com as encomendas dos paratextos antes de atingir o próprio texto literário: a partir dos exemplos acima, vemos como eram realizadas solicitações de prefácios aos escritores e de ilustrações aos artistas consagrados com o intuito de compor o enquadramento inédito das coleções, e só posteriormente estas encomendas chegaram ao texto propriamente dito.

Todavia, não podemos compreender obras inéditas como sinônimo de sob encomenda, embora o oposto seja verdadeiro. Vimos, por exemplo, que a editora Garnier tinha uma política de publicar obras inéditas dentro de uma coleção autoral, mas isto não significava que esta obra fosse encomendada. Aliás, percebemos que sobressaem três modelos de formatação do conjunto pelo projeto editorial de coleções temáticas: um constituído somente por obras anteriormente publicadas, mas que neste momento são trazidas para dentro de um discurso que as aproxima; um outro constituído somente por obras originais produzidas sob encomenda especificamente para compor a coleção; e aquele formato que mescla obras originais (encomendadas ou não) com outras reeditadas. Todas estas três possibilidades trabalham com uma (re)ordenação de uma rede de significados textuais e autorais, buscando destacar o conjunto perante o universo de infinitas publicações presentes no mercado, mas ao mesmo tempo gerando diferenças valorativas dentro deste próprio conjunto.

As coleções temáticas com textos inéditos e encomendados é uma realidade brasileira que se intensificou a partir da década de 1990, quando o mercado editorial brasileiro entrou de vez no fluxo internacional. Todavia, não é de se excluir algumas iniciativas anteriores, como a coletânea de contos Os sete pecados capitais, lançado em 1964 pela editora Civilização Brasiliense e que contou com a participação de autores nacionais consagrados. Pela mesma editora foi lançada, em 1965, uma outra coleção de contos, intitulada $O s d e z$ mandamentos. Mas, diferentemente do que ocorre a partir da última década do século XX, este modelo de obras sob encomenda proposto pela editora Civilização Brasileira não visava uma temática no nível dos romances, mas no dos contos; com isso, o formato de lançamento era diferente: naquela, um único livro temático, nas atuais, cada volume equivale a um romance encomendado e encarregado de uma fração da temática proposta.

Neste conceito de ineditismo no próprio conteúdo das obras, lançando coleções completamente escritas sob encomenda, o diferencial em relação às demais que até então compunham o mercado editorial brasileiro é que, agora, os editores responsáveis podem trabalhar com temáticas mais específicas, operando com maior proximidade em relação aos autores. Até então, tais editores atuavam como um curador que trabalhava com aquilo que já havia sido produzido por diferentes autores, tentando encontrar no meio desta multiplicidade de textos já existentes um fio narrativo coerente, o que fazia, inclusive, com que os títulos das coleções fossem bastante amplos - Grandes Sucessos, Os Imortais, Clássicos Brasileiros, etc. Mas, com tais coleções totalmente escritas sob encomenda, a situação se inverte, e o editor agora é um orquestrador que estipula pressupostos temáticos que antecedem à própria existência das obras, ditando premissas argumentativas para que os autores realizem suas escritas, construindo o que podemos definir como um "desafio de escrita".

Especificamente no caso de obras publicadas anteriormente e que são trazidas para dentro de um contexto de coleção, percebemos que acontece um rearranjo ou reafirmação do valor da obra e de seu autor, permitindo que lhe seja oferecida um reforço ou uma nova chave interpretativa. Assim, se a coleção funciona como uma nova forma de distribuição de obras já anteriormente publicadas, então, temos que perceber as alterações de significados que ela e seu autor sofreram ao longo de sua trajetória de distribuição e, consequentemente, recepção.

Por sua vez, as obras inéditas escritas para compor uma coleção inauguram uma posição possível dentro do campo, não havendo um antes a ser historicamente analisado, mas um nascer que exige uma disputa por um lugar próprio de enunciação vis-à-vis as demais, o que faz com que o estudo destas esteja direcionada para a trajetória autoral e para os espaços do possível que permitiram que esta obra surgisse, já que o campo permite invenções somente dentro dos limites aceitáveis pela sua gramática:

Para que as audácias da pesquisa [escrita] inovadora ou revolucionária tenham algumas possibilidades de ser concebidas, é preciso que existam em estado potencial no seio do sistema dos possíveis já realizados, como lacunas estruturais que parecem esperar e exigir o preenchimento, como direções potenciais de desenvolvimento, caminhos possíveis 
de pesquisa [escrita]. Mais do que isso, é preciso que tenham possibilidades de ser recebidas, isto é, aceitas e reconhecidas como 'razoáveis', pelo menos por um pequeno número de pessoas, aquelas mesmas que sem dúvida teriam podido concebê-las (BOURDIEU, 1996, p. 266) [grifos do autor, inserção nossa].

Esta escrita encomendada também opera no reposicionamento do próprio editor: se na organização de reedições ele poderia ser interpretado como um curador e um selecionador, agora, com essa possibilidade de encomendar uma escrita, ele também é capaz de se tornar um coautor em graus variados, desde os sutis manuseios do manuscrito com sugestões pontuais de orientação, até as mais dramáticas revisões e apontamentos de correções para tornar a obra vendável e/ou coerente com uma linha editorial. Estes limites do editor e da autoria se tornam mais embaçados, pois definir uma temática também traz certas imposições de uma escrita, já que o editor-curadorselecionador-coautor gera em si expectativas sobre como o escritor irá preencher o vazio narrativo construído pelas fronteiras temáticas que lhe foram propostas.

Com isso, nesta forma de coleções geradas a partir de obras encomendadas, o tema não mais surge das obras postas em comparação, mas da criatividade e das possibilidades de investimento das casas editoriais, o que, por um lado, abre um universo de infinitas possibilidades e, do outro, fazem com que os títulos das coleções também passem a ser mais específicos, trabalhados como nuances, tais como: Plenos Pecados (Ed. Objetiva, de 1998 a 2002), em que os autores convidados escreveram romances (e não mais contos, como ocorreu na década de 1960) pautados no tema dos sete pecados capitais; Literatura ou Morte (Ed. Cia. das Letras, de 2000) cujo intuito foi o desenvolvimento de uma história de mistério que ficcionalizasse a vida de algum escritor célebre da literatura mundial; Cinco dedos de prosa (Ed. Objetiva, publicados entre 2001 e 2004) em que cada autor escreveria sobre um dedo da mão; e Amores Expressos (Ed. Cia das Letras, iniciada em 2008) cujo argumento estabeleceu a construção de uma história de amor que tivesse como espaço de seus acontecimentos uma metrópole internacional. Outro exemplo seria a coleção Amores Extremos (Ed. Record, de 2001 a 2003), em que foram convidadas somente mulheres para escrever obras inéditas sobre o universo feminino: "literatura de casais. O homem e a mulher. A mulher sem o homem, o homem sem a mulher. A intimidade em vários cenários do amor na alma da mulher: o mito amoroso, o desejo, a dor, o reencontro" (RAMOS, 2009, p. 210).

Dessauer (1979, p.51) nos diz que "desde que haja interesse popular por determinado assunto haverá escritores que escreverão livros sobre ele e editores que os publicarão. Portanto, o horizonte para os livros de interesse geral é praticamente ilimitado e seus tópicos constituem uma inumerável legião de assuntos". Mas, na realidade, quando verificamos tais coleções, percebemos que todas estas produzem um recorte a partir de uma temática humanista e universalizante - pecado, morte, mistério, crime, amor, masculino e feminino - que servem muito bem a um mercado editorial que deseja construir uma ampla base de leitores até mesmo internacional, pois tais formatos não pretendem propor uma literatura com temáticas brasileiras: são argumentos que a literatura de massa já comprovou como sendo eficazes para captar a atenção do público leitor mediano. Como disse Koracakis (2004, p.04) sobre Literatura ou Morte, "o elemento parodístico também é algo implícito na encomenda desta coleção, sendo também o ponto de contato entre a vertente popular [representa pelo tom de mistério] e a 'erudita' [que surge na utilização de autores já mortos e suas obras consagradas para construir o argumento narrativo]" [inserção nossa]. Nesta perspectiva, o editor e o autor apelam ao popular mas fazem um clin d'oeil aos leitores sofisticados, o que abre a obra a diferentes camadas de leitura com o intuito de ampliar o público: "preserva-se o enredo, sem preconceito para com aquele leitor que visa divertir-se com a intriga. Por outro lado, oferece-se algo além da intriga, uma dimensão metalinguística e reflexiva, reforçada por inúmeras citações" (FIGUEIREDO, 2010, p. 61).

No caso desta conciliação entre uma temática clichê universalista e a sofisticação na linguagem, Barbosa (2013, p. 76) realiza o seguinte comentário sobre a coleção Amores Expressos:

Ainda que evoque uma literatura menor, destinada sobretudo às mulheres e de teor folhetinesco, literatura excessivamente romântica, que levou Madame Bovary ao seu trágico destino, literatura cor-de-rosa, de banca, das edições publicadas pela Harlequin, a temática do amor, tal como concebida pelo romantismo e explorada exaustivamente pelos folhetins da cultura de massa, embora insinuada no título da coleção, não se faz presente nas narrativas dos romances. Seus autores escolheram contornar o clichê, abordando o tema de maneira difusa ou então distante de sua concepção tradicional, ao que parece conscientes do perigo que corriam de descambar para a sua faceta convencional e desgastada, porque, ainda que seja válido resgatar o amor do ostracismo ao qual ele havia sido relegado, o tema deveria ressurgir, das cinzas, sob nova roupagem. Pode-se pensar também que o "amor" vem como uma chamada mercadológica, a fim de atrair um público desavisado e distraído, ao mesmo tempo que dá uma piscadinha de olho erudita e irônica ao leitor iniciado, atento, que haverá de reconhecer o nome de autores contemporâneos consagrados e celebrar a iniciativa. Atualiza-se, ainda, o tema do amor com o adjetivo "expresso", qualidade tão familiar ao nosso tempo (BARBOSA, 2013, p. 76). 
Desta forma, se os argumentos são considerados até mesmo clichês, as coleções encomendadas inovam ao tornar o "desafio", presente na composição, um vestígio fantasmático que inquieta o leitor que, então, busca julgar como o escritor deu conta em sua escrita dos argumentos temáticos propostos. Com isso, o leitor se insinua como um colecionador que recompõe em cada volume que lê o fracionamento temático imposto pelo editor, já que cada escritor e sua obra, representante de um volume dentro da coleção, é associado a um pecado, a um outro autor morto a ser transformado em personagem, a um dedo da mão, a uma cidade internacional, a uma possibilidade de vivência do feminino, etc. Operando uma estética da interrupção, é neste "desafio da escrita", que fraciona uma totalidade em volumes, que encontramos o ideal de raridade destas coletâneas encomendadas e idealizadas a partir de editor-curador.

Em termos de volumes previstos para compor a totalidade temática, também percebemos que algumas coleções são mais flexíveis do que outras: Plenos Pecados são sete, não poderia ser seis porque daria uma ideia de incompletude e nem oito porque extrapolaria o imaginário cristão; e o mesmo acontece com o Cinco dedos de prosa; já Literatura ou Morte foram seis, Amores Extremos sete e Amores Expressos dezessete, mas todas estas poderiam ser ampliadas ou reduzidas, já que o argumento não delimita a quantidade de fracionamentos temáticos, transparecendo a ideia de uma coleção aberta: se o número de volumes/ obras vislumbrado como sendo a referência de totalidade do conjunto não se tornar público desde o início, isto pode significar que a coleção traz em si uma potencialidade de expansão ou contração que reorganiza constantemente o ideário de completude. Neste sentido, Amores Expressos é uma coleção ainda em construção, mas que desde o início foram estipulados os seus limites: 17 autores contratados e enviados ao exterior para esta experiência internacional anterior à escrita, sendo que a tal fragmentação temática associou Amilcar Bettega a Istambul, Adriana Lisboa a Paris, André de Leones a São Paulo, Antonia Pellegrino a Bombaim, Antonio Prata a Xangai, Bernardo Carvalho a São Petersburgo, Cecilia Giannetti a Berlim, Chico Mattoso a Havana, Daniel Galera a Buenos Aires, Daniel Pellizzari a Dublin, João Paulo Cuenca a Tóquio, Joca Reiners Terron ao Cairo, Lourenço Mutarelli a Nova York, Luiz Ruffato a Lisboa, Paulo Scott a Sydney, Reinaldo Moraes a cidade do México e Sérgio Sant'Anna a Praga -, e isto, supostamente, levaria à composição de 17 obras como referência de totalidade.

Com ou sem número máximo de obras delimitado publicamente, isto não significa que haverá o lançamento de todas estipuladas pelos organizadores de tais coletâneas, ocorrendo uma contração desta quantidade que pode ter suas justificativas em questões comerciais e/ou estéticas.
Este é o caso de Amores Expressos: das dezessete obras previstas, a de André Leones já foi oficialmente recusada pela editora Companhia das Letras, sobre o pressuposto de que não atendeu às premissas do projeto e, assim, o autor acabou publicando-a em 2010 pela Editora Rocco e com o título Como desaparecer completamente. Outro romance recusado foi o de Cecilia Giannetti, cujo título provisório era Desde que eu te amo sempre. Tanto pelo número de lançamentos aumentado quanto reduzido em relação ao disposto inicialmente, há aqui uma sensação de dessacralização do colecionável: haverá sempre, principalmente no caso das obras abortadas, o sentimento de uma falta, fazendo mesmo surgir obras apócrifas como a de André de Leones e, possivelmente, a de Cecilia Giannetti.

Mas este problema da incompletude também surge com a questão da periodicidade de lançamento dos volumes. Se o ideal seria uma periodicidade ritmada para construir o leitor-colecionador que se projeta no que ainda está por vir, o que se vislumbra é uma fragmentação descompassada destes prazos de publicação, que aparentemente não estão contidos desde o início do projeto e, assim, fazem com que este se estenda por anos. Neste lento arrastar dos lançamentos, dos 07 livros do Plenos Pecados, 02 foram publicados em 1998, 03 em 1999 e os 02 últimos somente em 2002. Já Amores Extremos foram 03 em 2001, 02 em 2002 e mais 02 em 2003. Cinco dedos de prosa foram 02 em 2001, 01 em 2002 e 02 em 2004. Literatura ou Morte foi a mais concentrada, tendo todos seus seis livros vindo a público no ano de 2000.

A coleção que mais arrasta o seu término é mesmo Amores Expressos. Se o projeto surgiu em 2007, o primeiro lançamento ocorreu em 2008, com Cordilheira (Daniel Galera). O segundo e terceiro livros surgiram em 2009: Estive em Lisboa e lembrei de você (Luiz Ruffato) e $O$ filho da mãe (Bernardo Carvalho). Em 2010, foi a vez de $O$ único final feliz para uma história de amor é um acidente (João Paulo Cuenca) e Do fundo do poço se vê a Lua (Joca Reiners Terron). Já em 2011, a editora lançou O livro de Praga - narrativas de amor e arte (Sérgio Sant'Anna) e Nunca vai embora (Chico Mattoso). Finalmente, em 2013, mais três obras vieram à luz: Barreira (Amilcar Bettega), Digam ao Satã que o recado foi entendido (Daniel Pellizzari) e Ithaca Road (Paulo Scott). As obras vêm sendo publicadas paulatinamente: alguns anos vemos mais de uma sendo lançada enquanto outros passam em branco, em um processo lento que contrariou as expectativas de Rodrigo Teixeira, produtor cultural e idealizador do projeto: "o acordo estipulava que cada escritor teria um ano para concluir seu livro. "Nunca achei que demoraria tão mais que isso', diz Teixeira" (ALMEIDA, 2013, p.E1). 
Eis o atual balanço da coleção Amores Expressos: das 17 obras previstas, 10 foram lançadas, 02 recusadas, enquanto para as outras 05 ainda há esperanças.

Percebe-se que a elaboração de uma coleção temática sob encomenda faz rodar em paralelo dois tipos de projeto editorial: o das obras individualmente e o da coleção como um todo. E se Dessauer (1979, p. 09) nos diz que "cada livro é um produto novo e isolado, concebido, projetado e produzido separadamente, governado por um acordo distinto com seu autor [...]", logo, temos que levar em consideração que, se por um lado, os livros compõem uma coleção, por outro, eles são idealizados em relações distintas entre editor e autor, o que explica alguns já terem sido publicados, outros atrasados no prazo, e alguns ainda recusados. Todavia, a ideia de um projeto de coleção que possa incorporar novos autores e/ou que não tenha uma previsão final para as publicações cria uma tensão no próprio termo "projeto editorial" (pois este conceitualmente remete a um prazo de início e fim) e problematiza a "coleção" ao gerar uma situação de incerteza sobre o número real de volumes. É o que acontece com Amores Expressos.

Outro elemento que o projeto editorial de coleção nos faz pensar é no que tange ao suporte físico, pois se os textos devem ter uma mesma temática que os unem, é natural que algumas características materiais dos volumes também recebam um tratamento homogeneizante que estabeleça um padrão visual; afinal, o suporte onde se situa o texto também constrói significado, e por isso "a alma de um livro - suas ideias e seu conteúdo - deve ser preservada em um corpo apropriado [...]. Um planejamento visual bom e funcional ajuda a vender livros" (DESSAUER, 1979, p. 105). Nas coleções, é de se esperar que a temática componha uma identidade visual, materializando o conteúdo do texto na capa e contracapa.

Por exemplo, no site da Editora Objetiva (s/d) lemos que "Plenos Pecados tem projeto gráfico de Victor Burton, com imagens de artistas plásticos criadas especialmente para a coleção" e percebemos uma constância no uso de uma paleta com cores vermelhas nas capas e uma distribuição padronizada das informações (título, autor, nome da editora), tendo em destaque o nome da coletânea. Amores Extremos e Cinco dedos de prosa também obedecem a uma normatização visual, com o nome da coleção em evidência. Literatura ou Morte, embora tenha sido a única analisada que lançou todos seus livros no mesmo ano, apresenta confusão de estilos, com somente três visualmente harmonizadas e trazendo na capa o nome da coleção. Nenhuma destas traz numeração de volume, o que, se por um lado, inibe os ditames de uma ordem cronológica de leitura, por outro, em termos mercadológicos e de construção do sujeito colecionador, pode ser um problema, já que numerar significa indicar um trajeto e uma totalidade para a coleção, fazendo com que o leitor tenha uma melhor percepção sobre o volume que falta e onde ele se encaixa, em sua prateleira e em suas leituras.

Amores Expressos também não numera os volumes, e cada capa tem sua própria arte e diagramação, não seguindo nenhum modelo específico. A única referência se encontra na contracapa, onde se percebe, em uma estética de carimbo, a logomarca da coleção seguida do nome da cidade e do país ao qual o livro em mão ancora sua narrativa. Este mesmo carimbo, capaz de suscitar uma ideia de visto no passaporte, quando o viajante desembarca e passa pela imigração, sendo então "aprovado" pelos oficiais de chegada, aparece solitário na página de rosto e transforma, metaforicamente, o livro em uma territorialidade urbana que o leitor passa a ter permissão de entrar e folhear.

Fora estas duas carimbadas, que indicam a existência de um leitor-colecionador com vistos de entrada-leitura, os textos da contracapa e das orelhas dos livros buscam promover a narrativa da obra e o autor, sem nenhuma explicação que torne o livro reconhecido dentro de uma proposta de coleção. Carece nas obras impressas os dispositivos discursivos da coleção, cujos vestígios são praticamente inexistentes; e ao não estarem explícitos, os significados ocultos deste carimbo somente são acessados pelos leitores iniciados naquela transtextualidade aparada por outros suportes midiáticos de divulgação. Assim, o ideal de coletânea em Amores Expressos parece existir com maior visibilidade em outros circuitos, como os midiáticos que o promove, do que na materialidade dos romances lançados.

\section{Considerações finais}

Iniciadas ainda no século XIX, tais coleções temáticas chegaram ao XXI com outras configurações que demonstram uma intensa vontade das casas editoriais em inovar e buscar construir um conceito de raridade, com o intuito de se destacar e transformar o leitor em um colecionador. Assim, a partir da busca de um traçado possível sobre os projetos editoriais de coleções literárias, percebemos uma progressiva sofisticação desta estratégia mercadológica, principalmente quando vemos que o conceito de raridade - necessária a qualquer ato de colecionar - avançou do paratexto em direção aos textos propriamente dito, com coleções que não mais recuperam obras anteriormente editadas, mas que se propõem a lançar obras inéditas e exclusivas. Outra característica marcante diz respeito à translação das coletâneas dedicadas às obras completas de um determinado autor em direção às multiautorais, desviando a temática centrada em uma personalidade em direção a uma amplitude de argumentos possíveis, o que fortalece a ideia do editor enquanto um 
curador que lança um "desafio da escrita" aos autores que se comprometem a escrever sob encomenda.

Não queremos associar sob encomenda com qualidade literária, pois cremos ser este um caminho que não leva à uma sofisticação na crítica literária; todavia, seria interessante, em outro momento, descortinar o processo de recepção destas coleções, para entender até que ponto estes projetos editoriais são realmente percebidos e consumidos pelo leitor dentro da ideia de volumes e totalidades que lhe são propostos. Em outro momento, seria também oportuno analisar os títulos das obras que aparecem em uma determinada coleção, para verificar repetições e exclusividades que, no final, acabam por fortalecer ou construir o imaginário da totalidade discursiva colecionável.

Finalmente, reforçamos a importância dos estudos da literatura comparada na análise das obras que vêm à público dentro de uma proposta de coleção. A crítica literária que se debruça sobre tais obras deveria, preferencialmente, perceber a teia de significados que os textos produzem entre si, pois estes põem em prática uma vontade de totalidade temática construída por certos editores e tutoreada por autores convidados a este "desafio da escrita fracionada".

\section{Referências}

ALMEIDA, Marco Rodrigo. Amor por encomenda: atrasada, série Amores Expressos rende mais 3 livros e 'DR' sobre limites da literatura por encomenda. Folha de São Paulo [Ilustrada], São Paulo, p. E1, 27 jul. 2013.

BARBOSA, Aline Leal Fernandes. Literatura em tempos expressos. 2013. 115 f. Dissertação (Mestrado em Literatura, Cultura e Contemporaneidade) - Pontífica Universidade Católica, Rio de Janeiro.

BOURDIEU, Pierre. As regras da arte: gênese e estrutura do campo literário. São Paulo: Cia. das Letras, 1996.

DESSAUER, John P. Tudo sobre a publicação de livros: a experiência editorial nos Estados Unidos. São Paulo: Ed. Mosaico-EDUSP, 1979.
EDITORA OBJETIVA. Plenos Pecados. Disponível em: $<$ http://www.objetiva.com.br/colecao_ficha.php?id=18>. Acesso: 20 maio 2015.

FIGUEIREDO, Vera Follain de. Narrativas migrantes: literatura, roteiro e cinema. Rio de Janeiro: Ed. PUC-Rio: 7 letras, 2010 .

FOIS-BRAGA, Humberto. Trajetória histórica das coleções literárias: conceituações para os formatos de coletâneas seriadas e temáticas. Revista Trama (UNIOESTE. Online), Marechal Cândido Rondon, v. 12, p. 370-393, 2016.

HALLEWELL, Laurence. O livro no Brasil: sua história. São Paulo: USP, 2012.

ISHIBASHI, Masataka. Description de la Terre comme projet editorial: voyages extraordinaires de Jules Verne et système de l'éditeur Hetzel. 2007. 372f. Tese (Doutorado em Littérature et Civilisation Française) - Université Paris VIII, Paris, 2007.

KORACAKIS, Teodoro. As coleções ficcionais de encomenda na literatura brasileira (1995-2004). I Seminário Brasileiro sobre Livro e História Editorial, 01, 2004, Rio de Janeiro. Anais... Rio de Janeiro: Fundação Casa de Rui Barbosa e Universidade Federal Fluminense, 2004. p. 01-11.

OBRIST, Hans Ulrich. Caminhos da curadoria. Rio de Janeiro: Ed. Cobogó, 2014.

OLIVERO, Isabelle. L'invention de la collection. Paris: Éditions de l'IMEC, Éditions de la Maison des Sciences de l'Homme, 1999.

RAMOS, Tânia Regina Oliveira. Literaturas (ou leituras) sem vergonha. Revista Signótica, Goiânia, v. 21, n. 1, p.205-217, jan./jun. 2009.

REIMÃO, Sandra. Mercado editorial brasileiro: 1960-1990. São Paulo: COM-ARTE FAPESP, 1996.

\section{Autor:}

HUMBERTO FOIS-BRAGA

Universidade Federal de Juiz de Fora.

Juiz de Fora, MG, Brasil.

humfois@gmail.com

Recebido: $28 / 04 / 2017$

Aprovado: $28 / 04 / 2017$ 